\title{
Modeling of Two-Motor Front-Wheel Drive Control for Electric Vehicle with Electronic Differential Based on Energetic Macroscopic Representation
}

\author{
Ihor Shchur ${ }^{*}$, Ihor Havdo, Yurii Biletskyi \\ Lviv Polytechnic National University, 12 S. Bandera St., Lviv, 79013, Ukraine
}

Received: April 17, 2020. Revised: May 08, 2020. Accepted: May 15, 2020.

(c) 2020 The Authors. Published by Lviv Polytechnic National University.

\begin{abstract}
Unlike a car, a modern electric vehicle (EV) can have different configurations of the electrical traction subsystem using one, two or four drive-wheel electric motors. This paper investigates a two-motor front-wheel drive configuration, in which the control of the electromagnetic torques of the motors provides two functions: electric traction and direction control. The latter function performs an electronic differential, which is used in place of the traditional mechanical differential transmission and mechanical steering system. The implementation of the aforementioned functions has been put on the developed motor drive control system based on Ackermann-Jeantaud geometry. For the study of the experimental EV, a new energy-based approach for constructing mathematical models of complex systems - Energetic Macroscopic Representation (EMR) is used. According to the inverse principle provided by EMR, EV motion control system was developed. Conducted simulation studies in the software Matlab/Simulink showed the efficiency of the developed control system and high accuracy of maintaining the set speed and direction of motion in both steady and transient modes of EV.
\end{abstract}

Keywords: electric vehicle (EV); two-motor front-wheel drive; electronic differential; Energetic Macroscopic Representation (EMR).

\section{Definition of the problem to be solved}

Two global crises - environmental and energy - have led to the rapid and irreversible transition of humanity to autonomous electric transport. Electric vehicles (EV) beside environmental and energy advantages compared to internal combustion engine (ICE) cars have significant advantages in handling and reliability too. However, EVs also have problems, primarily related to the limited energy and long charging time of an on-board power supply and storage battery system. These problems raise new challenges for improving not only on-board power supplies, but for increase of energy efficiency in the operation of all other subsystems and devices of EVs [1]. First, it concerns the most energy-intensive energy consumer - the traction drive.

Unlike ICE cars, EVs traction subsystems can be built in different configurations. This feature gives new possibilities for quality control of vehicles, an increase of reliability and simplification of their mechanical design [2]. In particular, the configuration of the EVs with the individual drive of the two front wheels is promising. This configuration makes it possible to greatly simplify the mechanical transmission of the EV and replace the mechanical differential with an electronic one [3]. However, this configuration is not simple because of the complexity of automatic control. This is confirmed by the almost absence of this solution in the serial EVs of various world firms. Most of them go the easy way of creating a single motor drive.

For comprehensive research of new construction solutions and operation of such a complex object as EVs, a mathematical modelling is used. The new Energetic Macroscopic Representation (EMR) approach differs favorably

\footnotetext{
* Corresponding author. Email address: ihor.z.shchur@1pnu.ua
}

This paper should be cited as: I. Shchur, I. Havdo, Y. Biletskyi. Modeling of two-motor front-wheel drive control for electric vehicle with electronic differential based on energetic macroscopic representation. Energy Engineering and Control Systems, 2020, Vol. 6, No. 1, pp. 51 - 60. https://doi.org/10.23939/jeecs2020.01.051 
among various mathematical modelling technics. This approach makes it possible to integrate interconnected subsystems of different physical nature based on the energy principle of their operation, and provides a clear procedure for the construction of automatic control systems [4]. However, despite these advantages, the EMR approach is not widespread among researchers. Apart from our previous work [5], we did not find information about it use in publications of Ukrainian scientists.

\section{Analysis of the recent publications and research works on the problem}

EV power-train configuration, where two drive wheels are actuated by two separate traction motors through gearboxes and drive shafts or by two in-wheel motors, has the important advantage of quickly generating torque on each driven wheel [6]. By setting different values of the electromagnetic torques of the wheels, you can change their angular velocities in EV turns without using a mechanical differential gear. Such implementation, called the electronic differential, greatly simplifies the mechanical transmission and increases the reliability of the vehicle [7]. In the case of a two-motor EV configuration with the front drive wheels, the wheel electromagnetic torque control system also performs the steering function. In this case, it is advisable to eliminate the traditional steering gear with hydraulic or electric steering system and to steer virtually through wires by controlling the electromagnetic torque of the drive wheels, the so-called steer-by-wire control [8]. In addition, the front-wheel drives can perform the function of providing EV stability in cornering by a corresponding automatic reduction of wheel speed in the event of tire slip, the so-called yaw moment control [9]. As you can see, the two-motor front-drive EV configuration has extensive capabilities to ensure the handling and safety of the EV. However, this requires the creation of quite complicated control systems.

In order to test the efficiency of technical solutions regarding design and joint work of separate EVs subsystems, the mathematical modelling of EVs work in different modes is required. First, it concerns the subsystems of electric traction and on-board electric power supply, as well as justification of the parameters of individual components of these systems. In this case, computer simulations often have to be carried out over a long period, such as standard transport cycles. The French researcher A. Bouscayrol developed in 2000 the EMR approach for such complex tasks that combine the operation of systems of different physical nature [10]. This method is used for mathematical modelling of renewable energy systems, energy storage systems, electric and hybrid vehicles [11] - [13]. In [13], a front-drive EV system with two motors was simulated, however, the regularities of the electronic differential are too simplistic, and the steering system is generally replaced by the reference of the steering angle.

\section{Formulation of the goal of the paper}

The goal of the paper is to develop, based on the EMR approach, a mathematical model, which includes a complex subsystem of two-motor front-drive EV traction with electronic differential, performing the function of EV steering. The developed model is used to study the EV work and justify a number of its parameters.

\section{Presentation and discussion of the research results}

\subsection{Regularities of the work of the electronic differential}

In order to construct a mathematical model of EV motion, it is necessary to describe the kinematic regularities that occur during its turning [14]. The Ackermann-Jeantaud geometry (Fig.1), which underlies the construction of the steering systems of cars [3], is used for this purpose. Let EV moves at a speed $v$ determined from its gravity center $\mathrm{GC}$ and then makes a left turn at the steering angle $\delta$. Then the radii along which the right $R_{\mathrm{r}}$ and left $R_{1}$ wheels move are different. In order to minimize tire sliding, the angles of wheel turning are also different - the inner wheel turns at a greater angle than the outer wheel: $\delta_{1}>\delta_{\mathrm{r}}$. According to Fig.1, the values of these angles can be described as

$$
\delta_{\mathrm{r}}=\operatorname{arctg} \frac{L}{L / \operatorname{tg} \delta+d / 2} ; \quad \delta_{1}=\operatorname{arctg} \frac{L}{L / \operatorname{tg} \delta-d / 2},
$$

where $L$ is the wheelbase of $\mathrm{EV}$ and $d$ is the wheel track.

The radii along which the wheels move are respectively equal

$$
R_{\mathrm{r}}=L \sin ^{-1} \delta_{\mathrm{r}} ; \quad R_{1}=L \sin ^{-1} \delta_{1} .
$$




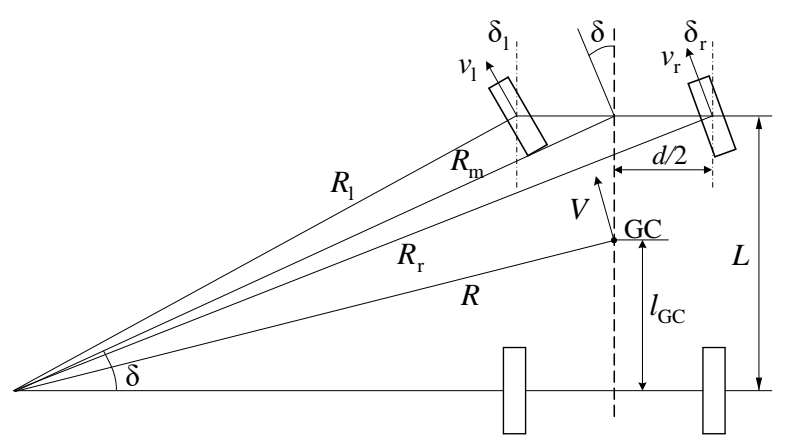

Fig.1. Ackermann-Jeantaud geometry.

The linear velocities of the wheels, respectively $v_{\mathrm{r}}$ and $v_{\mathrm{l}}$, are directly proportional to their radii of turning:

$$
\frac{v_{\mathrm{r}}}{R_{\mathrm{r}}}=\frac{v_{1}}{R_{\mathrm{l}}}=\frac{v_{\mathrm{m}}}{R_{\mathrm{m}}}=\frac{v}{R}
$$

where $R_{\mathrm{m}}$ is the radius of turning of the middle of the front axle and $R$ is the radius of turning of the GC (see Fig. 1).

The values of the indicated radii according to Fig. 1 are equal

$$
R_{\mathrm{m}}=\frac{L}{\sin \delta}, \quad R=\sqrt{\left(\frac{L}{\operatorname{tg} \delta}\right)^{2}+l_{\mathrm{GC}}^{2}}=L \sqrt{\operatorname{tg}^{-2} \delta+\left(l_{\mathrm{GC}}^{*}\right)^{2}},
$$

where $l_{\mathrm{GC}}^{*}=l_{\mathrm{GC}} / L$ is the relative position of the GC with respect to the back axle of EV.

\subsection{Development of EV control system}

Based on the obtained regularities of the electronic differential the general functional diagram of the electric traction system of two-motor front-drive EV (Fig.2) was developed. The driver using the EV control functions sets the reference values of the speed $v^{*}$ and the steering angle $\delta^{*}$ that come to the speed distributor SD. SD calculates the necessary values for speeds of the right $v_{\mathrm{r}}{ }^{*}$ and the left $v_{1}{ }^{*}$ wheels of the EV, which are the references for the respective wheel speed regulators $\mathrm{SR}_{\mathrm{r}}$ and $\mathrm{SR}_{1}$. At the output of the regulators, references for the electromagnetic torques of the drives of the right $T_{\mathrm{r}}{ }^{*}$ and left $T_{1}^{*} \mathrm{EV}$ wheels are formed. The right wheel drive and the left wheel drive systems work out the torques given to them and the corresponding traction forces of the wheels are formed

$$
F_{\mathrm{r}}=T_{\mathrm{r}} i / r_{\mathrm{w}} ; \quad F_{1}=T_{1} i / r_{\mathrm{w}},
$$

where $r_{\mathrm{w}}$ is the radius of the wheel and $i$ is the gear ratio of the gearbox through which the motor rotates the wheel.

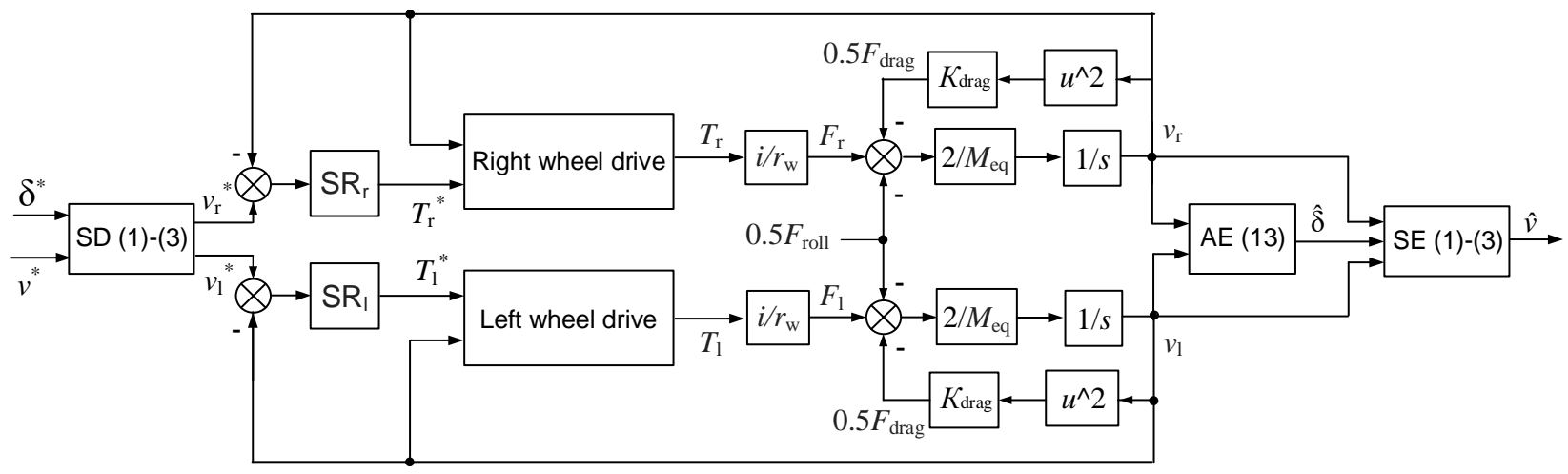

Fig.2. Functional diagram of the proposed two-motor front-drive EV traction system with electronic differential. 
With sufficient accuracy, it can be assumed that the EV resistance forces in the form of the rolling force $F_{\text {roll }}$ and the aerodynamic drag force $F_{\text {drag }}$ are evenly distributed between the right and left drive wheels. Then, the equations of the balance of forces acting in the places where the right and left wheels clutch with road will have the form

$$
0.5 M_{\mathrm{eq}} \frac{\mathrm{d} v_{\mathrm{r}}}{\mathrm{d} t}=F_{\mathrm{r}}-0.5\left(F_{\mathrm{roll}}+F_{\mathrm{drag}}\right) ; \quad 0.5 M_{\mathrm{eq}} \frac{\mathrm{d} v_{1}}{\mathrm{~d} t}=F_{1}-0.5\left(F_{\text {roll }}+F_{\mathrm{drag}}\right)
$$

where $M_{\mathrm{eq}}$ is the equivalent EV inertia mass, which takes into account its equipped mass $M_{\mathrm{EV}}$ and inertia of rotating parts, first of all are wheels with moments of inertia $J_{\mathrm{W}}$ :

$$
M_{\mathrm{eq}}=M_{\mathrm{EV}}+4 J_{\mathrm{w}} r_{\mathrm{w}}^{-2}
$$

The forces $F_{\text {roll }}$ and $F_{\text {drag }}$ are calculated by the following expressions

$$
F_{\text {roll }}=M_{\mathrm{EV}} g k_{\mathrm{r}} ; \quad F_{\mathrm{drag}}=0.5 \rho A_{\mathrm{f}} C_{\mathrm{d}} v^{2},
$$

where $\rho$ is the air density, $A_{\mathrm{f}}$ is an EV frontal area, and $C_{\mathrm{d}}$ is the aerodynamic drag coefficient of the EV body.

According to the traction forces of the wheels drives (5) and the equations of motion (6), the right and left EV wheels in cornering have different linear velocities $v_{\mathrm{r}}$ and $v_{\mathrm{l}}$. The linear velocity of the middle of the front axle, as well as the linear velocity of the GC based on (3) will be

$$
v_{\mathrm{m}}=\frac{R_{\mathrm{m}}}{R_{\mathrm{r}}} v_{\mathrm{r}}=\frac{R_{\mathrm{m}}}{R_{\mathrm{l}}} v_{1} ; \quad v=\frac{R}{R_{\mathrm{r}}} v_{\mathrm{r}}=\frac{R}{R_{\mathrm{l}}} v_{1} .
$$

Since all the radii included in (9) respectively depend on the EV steering angle $\delta$, it is necessary to obtain the online value of $\delta$ to determine the speeds $v$ and $v_{\mathrm{m}}$. EV wheel drive systems always have sensors of the angular velocities of the right $\omega_{\mathrm{r}}$ and the left $\omega_{1}$ wheels, therefore, the value of $\delta$ can be calculated by the angle estimator AE based on the signals from these sensors. Using (1) - (3), the following dependence is obtained

$$
\frac{\omega_{\mathrm{r}}}{\omega_{1}}=\frac{v_{\mathrm{r}}}{v_{1}}=\frac{R_{\mathrm{r}}}{R_{\mathrm{l}}}=\frac{\sin \left[\operatorname{arctg}\left(\operatorname{tg}^{-1} \delta-d /(2 L)\right)^{-1}\right]}{\sin \left[\operatorname{arctg}\left(\operatorname{tg}^{-1} \delta+d /(2 L)\right)^{-1}\right]} .
$$

Needed dependency $\hat{\delta}\left(\omega_{\mathrm{r}}, \omega_{1}\right)$ can be numerically obtained from (10) and presented in tabular form. In the case when one of the wheels slips, the AE will give a false value. However, such a situation is not a regular one, and its correction relies on another system that ensures course stability and is not the subject of the current study.

\subsection{Research approach}

The EMR approach that is used in this article provides a macroscopic view of the systems in terms of the energy processes that take place in them. The name EMR is described as follows: "Energetic" - the exchange of energy (power) between subsystems taking into account the principle of causality of energy connections; "Macroscopic" macroscopic description of processes in each subsystem with the formation of their inputs and outputs as two variables, which product is always a power; "Representation" means that a system is presented in the form of a mathematical graphical model in which subsystems are connected by the principle of "action - reaction".

Therefore, the EMR can be regarded as an intermediary step in the transformation of a complex real system into its computer model. The complex system is decomposed into basic interacting subsystems (Table 1): energy sources (green ellipses), energy storage elements (orange rectangles with diagonal), energy conversion elements without accumulation (various orange icons) and energy distribution elements (orange icons with overlaying). The control units and control strategy blocks are shown in light blue and blue parallelograms, respectively. Purple parallelograms display estimation blocks. 
Table 1. Elements of the EMR [10].

\begin{tabular}{|l|l|l|}
\hline Slectrical converter \\
(without energy accumulation)
\end{tabular}

The EMR approach is based on three fundamental principles [10], [11].

The principle of interaction. All elements of the system are connected according to the principle "action reaction" using the exchange of variables (arrays) (see Fig. 3 (a)). The product of the variables of action and reaction between the two elements is the instantaneous value of the power that these elements exchange.

The principle of causality. The EMR considers general causality. The elements of energy storage are determined by the time dependencies between their variables: their output quantities are integral functions of the input quantities. Other elements are described using non-integral time dependent interactions.

The principle of inversion. The structure of the control system is regarded as an inversion of the simulated system: control determines the input quantities that are come to the system depending on the desired output values (see Fig. 3 (b)). In this approach, time-independent relationships are directly inverted (without any control or measurement). Because dependencies with derivatives are unresolved, direct inversion of time dependencies is impossible. Indirect inversion uses regulators and feedbacks. Each block of the simulated system has its own control system block. They are usually parallel to each other.

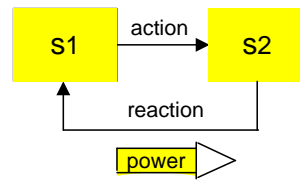

(a)

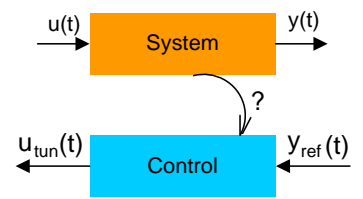

(b)

Fig.3. Basic principles of the EMR: (a) Interaction principle, (b) Inversion-based control principle.

\subsection{Creating an EMR model}

The EMR model of the studied two-motor front-drive EV with electronic differential (Fig.4) was developed according to the basic principles of the EMR approach and in accordance with the functional diagram shown in Fig.2.

In the block "DC source" we used the battery which forms an on-board DC-bus with the voltage $V_{\mathrm{B}}$. In complex studies, the operation of the battery can be sufficiently accurately described by the following equation:

$$
V_{\mathrm{B}}=E_{\mathrm{B}}-I_{\mathrm{B}} R_{\mathrm{B}},
$$

where $E_{\mathrm{B}}$ is the battery electromotive force $(\mathrm{EMF}), I_{\mathrm{B}}$ is the battery current, and $R_{\mathrm{B}}$ is the battery internal resistance.

The battery powers both the right and left wheel drive systems. In the model, this is represented by the "Current distribution" block, which distributes the $V_{\mathrm{B}}$ into two power supply circuits of the DC-DC converters of the right and left wheel drives. The currents of the converters are summed up in the battery: $I_{\mathrm{B}}=I_{\mathrm{DC}-\mathrm{DC} . \mathrm{r}}+I_{\mathrm{DC}-\mathrm{DC} .1}$.

For the drive of modern EVs, usually, alternating current drives are used, which operate in the mode of electromagnetic torque regulation. In this case, vector control methods are used that are close in quality to the voltage control of the DC motor. Therefore, in this study, the operation of the real electric drive system was replaced by the 
equivalent operation of the system "DC-DC converter - DC motor". The buck type DC-DC converter is modeled as an inertia-free and loss-free voltage regulator working under the law

$$
V_{\mathrm{a} . \mathrm{r}(\mathrm{l})}=m_{\mathrm{r}(\mathrm{l})} V_{\mathrm{B}} ; \quad I_{\mathrm{DC}-\mathrm{DC} . \mathrm{r}(\mathrm{l})}=m_{\mathrm{r}(\mathrm{l})} I_{\mathrm{a} . \mathrm{r}(\mathrm{l})},
$$

where $V_{\text {a.r(l) }}$ and $I_{\text {a.r(l) }}$ are the voltages and currents of the right and left DC motors respectively, $m_{\mathrm{r}(1)}$ are the transmission coefficients for the voltage of the DC-DC converters of the right and left wheels drives.

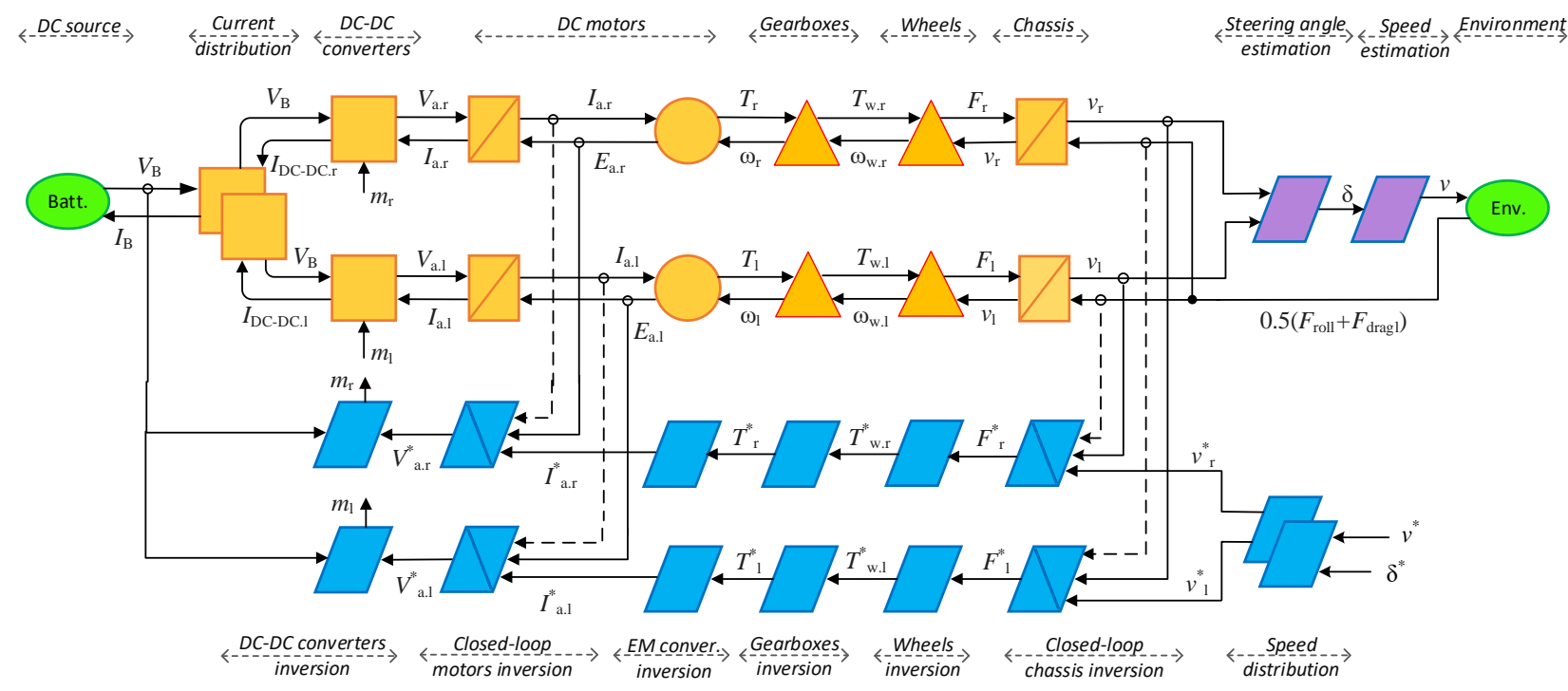

Fig.4. The EMR model of two-motor front-wheel-drive EV with electronic differential.

"DC motors" blocks consist of two connected subsystems. The first subsystem is the energy storage element, which is an armature winding of the motor and is described by the following equation of voltage balance

$$
L_{\mathrm{a}} \frac{\mathrm{d} I_{\mathrm{a} . \mathrm{r}(\mathrm{l})}}{\mathrm{d} t}=V_{\mathrm{a} . \mathrm{r}(\mathrm{l})}-E_{\mathrm{a} . \mathrm{r}(\mathrm{l})}-I_{\mathrm{a} . \mathrm{r}(\mathrm{l})} R_{\mathrm{a}}
$$

where $L_{\mathrm{a}}$ and $R_{\mathrm{a}}$ are the inductance and active resistance of the armature winding, $E_{\mathrm{a} . \mathrm{r}(\mathrm{l})}$ are the EMF of the right and left DC motors.

The second subsystem is the multiphysical element of energy conversion. Its work is described by known equations of electromechanical conversion in DC motor:

$$
T_{\mathrm{r}(\mathrm{l})}=k \Phi I_{\mathrm{ar}(\mathrm{l})} ; \quad E_{\mathrm{a} . \mathrm{r}(\mathrm{l})}=k \Phi \omega_{\mathrm{r}(\mathrm{l})},
$$

where $T_{\mathrm{r}(\mathrm{l})}$ and $\omega_{\mathrm{r}(\mathrm{l})}$ are the torques and angular speeds of the right and left DC motors respectively, $k \Phi$ is the backEMF constant of the DC motor that equal to the product of the structural machine constant per excitation flux.

Blocks of mechanical energy conversion "Gearboxes" reflect the regularities of perfect mechanical transmission of torques $T$ and angular speeds $\omega$ between the DC motors and EV wheels $(\omega)$ :

$$
T_{\mathrm{w} . \mathrm{r}(\mathrm{l})}=i T_{\mathrm{r}(\mathrm{l})} ; \quad \omega_{\mathrm{r}(\mathrm{l})}=i \omega_{\mathrm{w} \cdot \mathrm{r}(\mathrm{l})}
$$

"Wheels" blocks reflect the regularities of converting EV wheels rotating motion into them translational motion according to the equations

$$
F_{\mathrm{r}(\mathrm{l})}=T_{\mathrm{w} . \mathrm{r}(\mathrm{l})} / r_{\mathrm{w}} ; \quad \omega_{\mathrm{w} . \mathrm{r}(\mathrm{l})}=v_{\mathrm{r}(\mathrm{l})} / r_{\mathrm{w}} .
$$


In the EMR, "Chassis" blocks are considered as elements of EV half that can store energy because they take into account such parameter as EV mass. The inputs of these subsystems are powered by traction wheel forces, which should provide the required speeds. The actual values of these speeds by causality will be the outputs of blocks that cannot rise or fall in an instant. The second outputs will have the same speed values and the second inputs will be the forces opposing the motion. The work of these blocks is described by equations (6).

The "Environment" block generates the resistance driving forces $F_{\text {roll }}$ and $F_{\text {drag }}$ according to equations (8) and evenly distributes them between the two EV wheels: $F_{\text {env }}=0.5\left(F_{\text {roll }}+F_{\text {drag }}\right)$.

The control blocks are highlighted in light blue and arranged in parallel to the corresponding blocks of the simulated system. All control blocks without controllers are constructed with clearly inverse mathematical expressions, which are inverted to their blocks of the simulated system. For example, for "Gearboxes inversion" control blocks that are inverted to "Gearboxes" blocks, instead of equations (15), we obtain their inverse expressions:

$$
T_{\mathrm{r}(\mathrm{l})}^{*}=i^{-1} T_{\mathrm{w} . \mathrm{r}(\mathrm{l})}^{*}, \quad \omega_{\mathrm{r}(\mathrm{l})}^{*}=i^{-1} \omega_{\mathrm{w} . \mathrm{r}(\mathrm{l})}^{*}
$$

References for the control system are formed by separate subsystem (not shown in Fig. 4) as time dependencies of the EV speed of motion $v^{*}(t)$ and the steering angle $\delta^{*}(t)$. The "Speed distribution" block provides the distribution of the speed reference between the wheel drives according to equations (1) - (3) coming to the blocks "Closed-loop chassis inversion". Since energy is stored in the "Chassis" blocks, it is impossible to realize direct inversion. Separate closed loops must be implemented for such subsystems. In this case, they will be the speed controllers of the right and left EV wheels, which are built according to expressions:

$$
F_{\mathrm{r}(\mathrm{l})}^{*}=K_{\mathrm{p} . \mathrm{V}}\left[v_{\mathrm{r}(\mathrm{l})}^{*}(t)-v_{\mathrm{r}(\mathrm{l})}(t)\right]+F_{\mathrm{env}}(t)
$$

where $K_{p . V}$ is the gain factor of the speed controllers.

The outputs of the blocks "Closed-loop chassis inversion" form references for the wheels traction forces $F_{\mathrm{r}(1)}^{*}$, which drives have to be developed to achieve the set wheel speeds.

According to a similar principle, closed systems for regulating the armature DC currents of electric motors are built because of magnetic field energy is accumulated in their armature windings. Therefore, in the blocks "Closedloop motors inversion" implemented the current controllers of DC motors according to the equations

$$
V_{\mathrm{DC}-\mathrm{DC} . \mathrm{r}(\mathrm{l})}^{*}=K_{\mathrm{p} . \mathrm{I}}\left[I_{\mathrm{a} . \mathrm{r}(\mathrm{l})}^{*}(t)-I_{\mathrm{r}(\mathrm{l})}(t)\right]+E_{\mathrm{a} . \mathrm{r}(\mathrm{l})}(t)
$$

where $K_{\mathrm{p.I}}$ is the gain factor of the current controllers.

The outputs of the "Closed-loop motors inversion" blocks are the references for the output voltages of the blocks

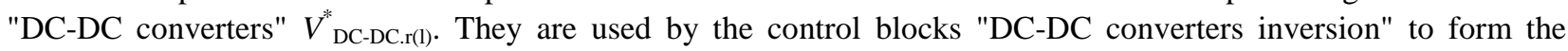
required values of the transmission coefficients of the DC-DC converters:

$$
m_{\mathrm{r}(1)}=V_{\mathrm{DC}-\mathrm{DC} . \mathrm{r}(\mathrm{l})}^{*} / V_{\mathrm{B}}
$$

The blocks of estimation "Steering angle estimation" and "Speed estimation" carry out the calculation of the obtained values of the steering angle $\delta$ and the EV speed $v$ respectively, as shown in the functional diagram in Fig. 3.

\subsection{Simulation results}

An EV based on the chassis of the Audi A2 was selected for the study. Table 2 shows the basic parameters of this vehicle that are necessary for modelling of its operation. It is accepted that after conversion of this car into a twomotor front-drive EV with electronic differential, the curb weight of the EV will grow to $1200 \mathrm{~kg}$ due to the weight of the battery. Consumer EV settings were selected as follows: the maximum acceleration of $2.78 \mathrm{~m} / \mathrm{s}^{2}$ (acceleration to $100 \mathrm{~km} / \mathrm{h}$ in $10 \mathrm{~s}$ ), the maximum speed of $140 \mathrm{~km} / \mathrm{h}$. For two-zone speed control of electric motors, their nominal angular velocity is chosen corresponding to the EV speed of $60 \mathrm{~km} / \mathrm{h}$. Under such conditions, as shown by the 
calculations, the rated power of the motors, which allow $2.5 \mathrm{x}$ overload at a torque, will be $14.3 \mathrm{~kW}$. Basing on this, as well as accepting that the motors are connected to the wheels via planetary gearboxes with a gear ratio $i=3.6$, other parameters of the driving DC motors are given in Table 3. The voltage of the onboard DC-bus and hence the nominal voltage of the battery is taken to be $V_{\mathrm{B}}=350 \mathrm{~V}$.

Table 2. Parameters of the EV.

\begin{tabular}{|l|c|l|c|}
\hline \multicolumn{1}{|c|}{ Parameters } & Values & \multicolumn{1}{|c|}{ Parameters } & Values \\
\hline EV mass $M_{\mathrm{EV}}(\mathrm{kg})$ & 1200 & Gear ratio $i$ & 3.6 \\
Front track $d(\mathrm{~m})$ & 1.47 & Tire radius $r_{\mathrm{w}}(\mathrm{m})$ & 0.293 \\
Wheel base $L(\mathrm{~m})$ & 2.405 & Wheel inertia $J_{\mathrm{w}}\left(\mathrm{kg} \cdot \mathrm{m}^{2}\right)$ & 1.8 \\
Position of $\mathrm{GC} l_{\mathrm{GC}}^{*}$ & 0.55 & Rolling resistance & 0.015 \\
Frontal area $A_{\mathrm{f}}\left(\mathrm{m}^{2}\right)$ & 2.05 & coefficient $k_{\mathrm{r}}$ & \\
Aerodynamic drag coefficient $C_{\mathrm{d}}$ & 0.3 & & \\
\hline
\end{tabular}

Table 3. Parameters of the DC Motors

\begin{tabular}{|l|c|l|c|}
\hline \multicolumn{1}{|c|}{ Parameters } & Values & \multicolumn{1}{|c|}{ Parameters } & Values \\
\hline Rated power $P_{\mathrm{n}}(\mathrm{kW})$ & 14.3 & Rated efficiency $\eta_{\mathrm{n}}$ & 0.92 \\
Rated speed $n_{\mathrm{n}}(\mathrm{rpm})$ & 1977 & Armature resistance $R_{\mathrm{a}}(\Omega)$ & 0.42 \\
Rated torque $T_{\mathrm{n}}(\mathrm{Nm})$ & 68.9 & Armature inductance $L_{\mathrm{a}}(\mathrm{H})$ & 0.0105 \\
Rated voltage $V_{\text {a.n }}(\mathrm{V})$ & 300 & Back-EMF constant $k \Phi_{\mathrm{n}}(\mathrm{V} \cdot \mathrm{s})$ & 1.33 \\
Rated current $I_{\mathrm{a} . \mathrm{n}}(\mathrm{V})$ & 57.3 & Moment of inertia $J(\mathrm{~kg} \cdot \mathrm{m} 2)$ & 0.023 \\
\hline
\end{tabular}

The computer model of the investigated EV was constructed in Matlab/Simulink in strict accordance with the EMR model shown in Fig. 4. In this case, each block is represented as a subsystem depicted similarly to a block in which the mathematical models described above are implemented. The models of energy storage subsystems use the transfer functions of objects derived from differential equations (13) and (6). In their respective control subsystems described by equations (18) and (19), P-controllers with the following parameters are used: for speed control $K_{\mathrm{p} . \mathrm{V}}=$ 10000 and for current control $K_{\text {p.I }}=20$.

The "Speed distribution" and "Speed estimation" subsystems require some explanation.

In the "Speed distribution" subsystem, the reference values of EV wheel speeds are calculated using the following expressions obtained from (1) - (3):

$$
\begin{aligned}
& v_{\mathrm{r}}^{*}=\sin ^{-1}\left[\operatorname{arctg}\left(\operatorname{tg}^{-1} \delta-d /(2 L)\right)^{-1}\right] \cdot\left[\operatorname{tg}^{-2} \delta+\left(l_{\mathrm{GC}}^{*}\right)^{2}\right]^{-0.5} v^{*} \\
& v_{1}^{*}=\sin ^{-1}\left[\operatorname{arctg}\left(\operatorname{tg}^{-1} \delta+d /(2 L)\right)^{-1}\right] \cdot\left[\operatorname{tg}^{-2} \delta+\left(l_{\mathrm{GC}}^{*}\right)^{2}\right]^{-0.5} v^{*}
\end{aligned}
$$

It should be noted that equations (21) and (22) are valid only for the left turning of the EV, as shown in Fig. 1. In the right turning, the expressions for $v_{\mathrm{r}}^{*}$ and $v_{1}^{*}(21)$ and (22) must be interchanged and the sign of the steering angle $\delta$ should not be taken into account. In straight-line motion $(\delta=0)$, expressions (21) and (22) lose their definiteness. Therefore, in the model, for $\delta<1^{\circ}, v_{\mathrm{r}}^{*}=v^{*}{ }_{1}=v^{*}$ was accepted.

In the "Speed estimation" subsystem, based on the measured real values of the $v_{\mathrm{r}}$ and $v_{\mathrm{l}}$, the steering angle $\delta$ is first calculated using the expression (10). For this purpose, a pre-tabulated function $\hat{\delta}\left(v_{\mathrm{r}} / v_{1}\right)$ with the parameters of investigated EV was obtained and represented in the model by the "Look-up-Table" block. Further, the EV velocity is calculated for one of the expressions similar to (21) or (22). In the right turning, it is necessary to interchange the numerator and denominator in (10), consider the minus value of $\delta$, and the expressions in (21) and (22) also need to be interchanged and used the module of $\delta$.

The results of computer simulation are presented in Fig.5

As can be seen from Fig.5(a) and Fig.5(b), motors control systems work precisely and the values of EV speed $v$ and steering angle $\delta$ are practically the same as their set references. To verification the controllability of EV in the test section of its motion, it is given the following cornering: $30^{\circ}$ to the left at a speed of $30 \mathrm{~km} / \mathrm{h}, 10^{\circ}$ to the right at a 
speed of $55 \mathrm{~km} / \mathrm{h}$, and $15^{\circ}$ to the left before the start and in the braking process (see Fig.5(b)). The wheel speed distribution subsystem according to (21) and (22) sets the references $v_{\mathrm{r}}^{*}$ and $v_{1}^{*}$ for the wheel drives, which are clearly worked out by the control systems (see Fig.5(c)). Time dependencies in Fig.5(d), Fig.5(e) and Fig.5(f) demonstrate, respectively, the traction forces of the right and left wheels, the currents of the motors forming these forces, and the voltages of the armatures of the motors in the processes of forming the currents.

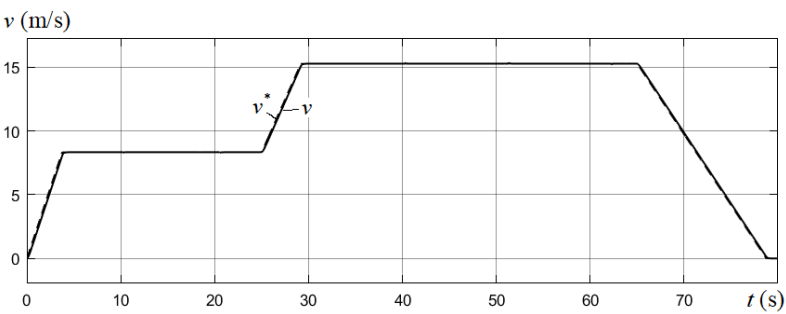

(a)

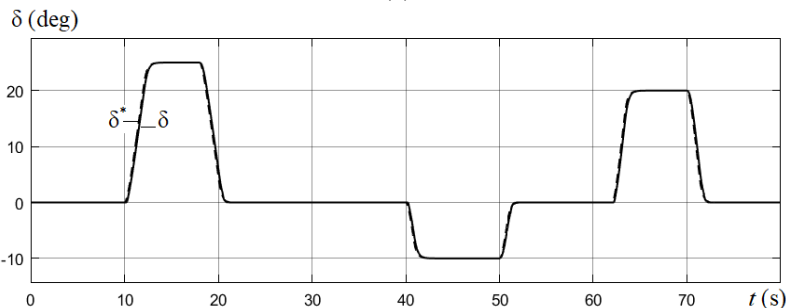

(b)

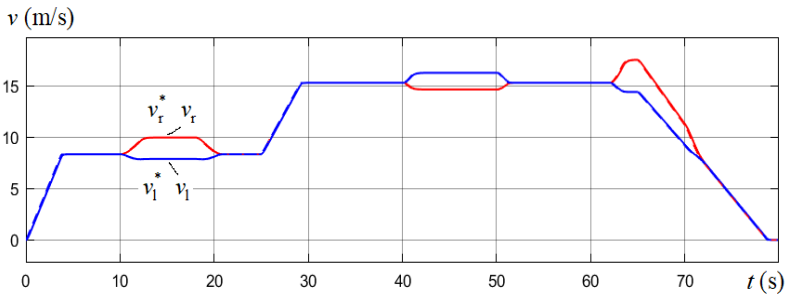

(c)

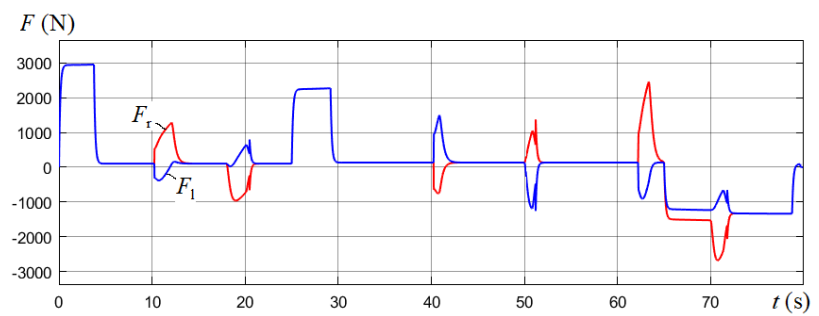

(d)

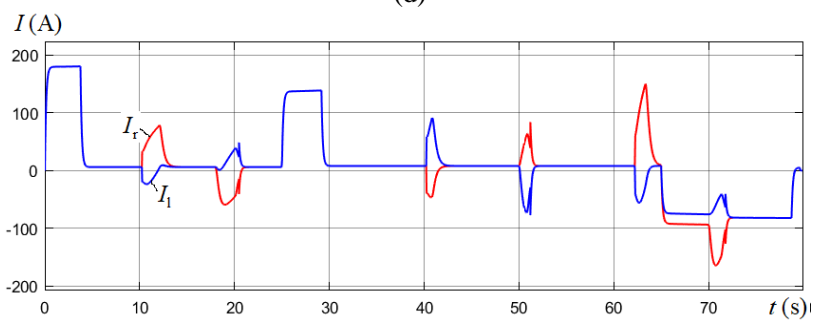

(e)

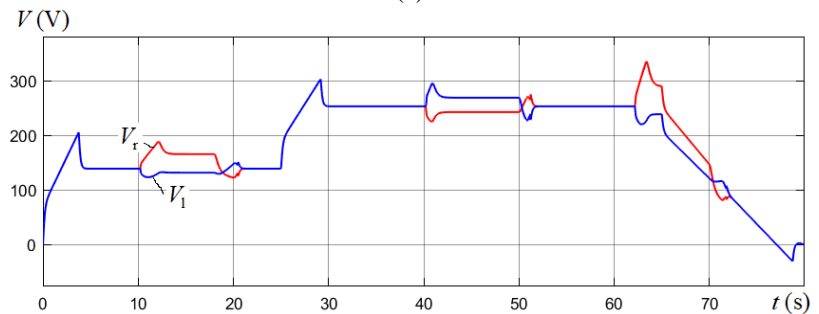

(f)

Fig.5. Results of computer simulation: (a) EV speed reference and its real value, (b) steering angle reference and its real value, (c) right and left wheels speeds references and their real values, (d) right and left wheels forces references and their real values, (e) right and left wheels motors currents and their real values, (f) right and left wheels motors voltages and their real values.

\section{Conclusion}

The presence of an electronic differential considerably simplifies the mechanical construction of an EV, reduces its mass and increases reliability. It is also possible to easily implement various active safety systems, such as course stability and electronic brake systems.

The EMR approach allows simulating complex systems in which subsystems of different physical nature are combined. Using the principle "action - reaction", the EMR makes it possible to present the system in the form of interconnected blocks with input and output energy characteristics and implement of control structure clearly based on inversion.

Based on Ackermann-Jeantaud geometry, the wheel drive control system ensures high precision torque forming on each wheel and, accordingly, their speed providing EV cornering without wheel slip, ensuring driving safety and tire durability.

\section{References}

[1] Stippich, A., van der Broeck, C.H., Sewergin, A. and Wienhausen, A.H. (2017) Key Components of Modular Propulsion Systems for Next Generation Electric Vehicles. CPSS Trans. Power Electronics and Applications, 2(4), $249-258$. http://dx.doi.org/10.24295/CPSSTPEA.2017.00023

[2] Kumar, L. and Jain, S. (2014) Electric Propulsion System for Electric Vehicular Technology: A Review. Renewable and Sustainable Energy Reviews, 29, 924-940. http://dx.doi.org/10.1016/j.rser. 2013.09.014 
[3] Yildirim, M., Oksuztepe, E., Tanyeri, B. and Kurum H. (2015) Electronic Differential System for an Electric Vehicle with In-Wheel Motor. Proc. 9th Int. Conf. on Electrical and Electronics Engineering (ELECO), 26-28 Nov. 2015, Bursa, Turkey, 1048-1052. http://dx.doi.org/10.1109/ELECO.2015.7394567

[4] EMR Website. Energetic Macroscopic Representation. http://www.emrwebsite.org/energetic-macroscopic-representation.html

[5] Shchur, I., Kasha, L. and Bukavyn, M. (2020) Efficiency Evaluation of Single and Modular Cascade Machines Operation in Electric Vehicle. Proc. 15th IEEE Int. Conf. on Advanced Trends in Radioelectronics, Telecommunications and Computer Engineering (TCSET2020), 25 - 29 Feb., 2020, Lviv - Slavske, Ukraine. - 6 p.

[6] Yildirim, M., Polat, M. and Kurum, H. A (2014) Survey on Comparison of Electric Motor Types and Drives Used for Electric Vehicles. Proc. IEEE 16th Int. Power Electronics and Motion Control Conf. and Exposition (PEMC), 21-24 Sept. 2014, Antalya, Turkey, 218-223. http://dx.doi.org/10.1109/EPEPEMC.2014.6980715

[7] Uysal, A. and EmelSoylu, E. (2017) Embedded System Design and Implementation of an Intelligent Electronic Differential System for Electric Vehicles. Int. J. Advanced Computer Science and Applications (IJACSA), 8(9), 129-134. http://dx.doi.org/10.14569/IJACSA.2017.080918

[8] Tumari, M.Z.M., Saealal, M.S., Abd Rashid, W.N., Saat, S. and Mohd Nasir, M.A. (2017) The Vehicle Steer by Wire Control System by Implementing PID Controller. J. Telecommunication, Electronic and Computer Engineering, 9(3-2), 43-47.

[9] Hu, J.-S., Lin, X.-C. and Hu, F.-R. (2014) Direct Yaw-Moment Control for In-wheel Motor Electric Vehicles. Proc. IEEE/SICE Int. Symp. System Integration, 13-15 Dec., 2014, Tokyo, Japan, 475-479. http://dx.doi.org/10.1109/SII.2014.7028085

[10] Lemaire-Semail, B., Lhomme, W., Bouscayrol, A. and Barrade P. (2014) Energetic Macroscopic Representation. Seminar Sept. 2014. http://www.emrwebsite.org/uploads/Fichiers/EPFL-2014/3-EMR.pdf

[11] Depature, C., Lhomme, W. and Bouscavrol A. (2013) Teaching Electric Vehicle Drive Control Using Energetic Macroscopic Representation. Proc. 2013 World Electric Vehicle Symposium and Exhibition, 17-20 Nov. 2013, Barcelona, Spain, 6 p. http://dx.doi.org/10.1109/EVS.2013.6914831

[12] Chen, K., Bouscayrol, A., Berthon, A., Delarue, P., Hissel, D. and Trigui R. (2008) Global Modeling of Different Vehicles Using Energetic Macroscopic Representation. Proc. IEEE Vehicle Power and Propulsion Conf., 3-5 Sept. 2008, Harbin, China, 533-539. http://dx.doi.org/10.1109/VPPC.2008.4677728

[13] Chen, K., Bouscayrol, A. and Lhomme, W. (2008) Energetic Macroscopic Representation and Inversion-based Control: Application to an Electric Vehicle with an Electrical Differential. J. Asian Electric Vehicles, 6(1), 234-239. https://doi.org/10.4130/jaev.6.1097

[14] Shchur, I. (2019) Active Steering System in the Electronic Differential of the Electric Vehicle with the Individual Drive of the Two Front Wheels. Bulletin of the National Tech. University «KhPI». Series: Problems of Automated Electric Drive. Theory and Practice, 16'2019. 99-104. http://dx.doi.org/10.20998/2079-8024.2019.16.18 (in Ukrainian)

\title{
Моделювання керування дводвигунним передньопривідним електромобілем з електронним диференціалом за принципом макроенергетичного представлення
}

\author{
Ігор Щур, Ігор Гавдьо, Юрій Білецький \\ Найіональний університет «Львівська політехніка», вул. С. Бандери, 12, м. Львів, 79013, Украӥна
}

\section{Анотація}

На відміну від автомобіля, сучасний електромобіль (ЕМ) може мати різні конфігурації підсистеми електричної тяги із застосуванням одного, двох чи чотирьох привідних електричних двигунів коліс. У цій роботі досліджується передньопривідна дводвигунна конфігурація з незалежним приводом коліс, в якій регулюванням електромагнітних моментів двигунів забезпечується виконання двох функцій: електричної тяги та керування напрямком руху. Остання функція виконується електронним диференціалом, який застосовується замість традиційної механічної диференціальної передачі та механічної системи рульового керування. Виконання вказаних функцій покладено на розроблену на основі геометрії Ackermann-Jeantaud систему керування привідними двигунами. У роботі для дослідження роботи дослідного ЕМ застосовано новий підхід до побудови математичних моделей складних систем на енергетичній основі макроенергетичне представлення (EMR). За інверсним принципом, передбаченим EMR, розроблено систему керування рухом ЕM. Проведені симуляційні дослідження в середовищі MatLab/Simulink показали працезданість розробленої системи керування та високу точність підтримання заданих швидкості та напрямку руху як в усталених, так і в перехідних режимах роботи ЕМ.

Ключові слова: електромобіль; дводвигунний передній привід; електронний диференціал; макроенергетичне представлення. 